\title{
Intraoperative Radiation Therapy
}

National Cancer Institute

\section{Source}

National Cancer Institute. Intraoperative Radiation Therapy. NCI Thesaurus. Code C15623.

The use of any form of radiation therapy during a surgical procedure. 